\title{
Expression and modulation of Rho kinase in human pregnant myometrium
}

\author{
C.J.Moran' ${ }^{1}$, A.M.Friel ${ }^{1,2}$, T.J.Smith ${ }^{2}$, M.Cairns ${ }^{2}$ and J.J.Morrison ${ }^{1}$ \\ ${ }^{1}$ Department of Obstetrics and Gynaecology, National University of Ireland Galway, Clinical Science Institute, University College \\ Hospital, Newcastle Road, Galway and ${ }^{2}$ National Diagnostics Centre, BioResearch Ireland, National University of Ireland Galway, \\ University Road, Galway, Ireland \\ ${ }^{3}$ To whom correspondence should be addressed. E-mail: john.morrison@ nuigalway.ie
}

There is little information outlining the role of Rho kinase, RhoA, and calcium sensitization in regulation of human uterine contractility during pregnancy. The aims of this study were to investigate the expression of RhoA, and the Rho kinases ROCK I and ROCK II in human pregnant myometrium, to evaluate the effects of Rho kinase inhibition on pregnant human myometrial contractility in vitro, and to compare these effects with those of the calcium channel blocker nifedipine. RT-PCR using primers for RhoA, ROCK I and ROCK II was performed on mRNA isolated from human pregnant myometrium. Isometric recording was performed in isolated myometrial strips obtained at Caesarean section. The effects of the Rho kinase inhibitor Y-27632 $(1 \mathrm{nmol} / \mathrm{l}$ to $10 \mathrm{mmol} / \mathrm{l})$, and nifedipine $(1 \mathrm{nmol} / \mathrm{l}$ to $10 \mathrm{mmol} / \mathrm{l})$, on oxytocin $(0.5 \mathrm{nmol} / \mathrm{l})$ induced contractions were measured and compared. Expression of RhoA, ROCK I and ROCK II mRNA was identified in human pregnant myometrium $(n=3)$. Y-27632 exerted a potent relaxant effect on myometrial contractility with a $\mathrm{pD}_{2}$ value $( \pm \mathrm{SEM})$ of $7.63 \pm 0.38(n=6)$. The maximum net relaxant effect $( \pm$ SEM) was $72.3 \pm 6.1 \%(n=6)$. Corresponding values for nifedipine were $7.24 \pm 0.48$ $(n=6 ; P=0.469)$ and $93.40 \pm 3.1 \%(n=6 ; P=0.028)$. Rho $\mathrm{A} /$ Rho kinase-mediated calcium sensitization may play role in the physiology of human parturition, and pharmacological inhibition of this pathway may therefore provide a novel approach to tocolysis for pre-term labour.

Key words: human myometrium/preterm labour/Rho kinase/tocolysis

\section{Introduction}

The delivery of infants preterm is a major cause of perinatal morbidity and mortality in current obstetric practice (Goldenberg and Rouse, 1998). A significant proportion of all preterm deliveries $(\sim 30-50 \%)$ is related to spontaneous idiopathic preterm labour (Ianuchi et al., 1996; Burke and Morrison, 2000). At present, no satisfactory therapeutic intervention exists for this clinical problem (Morrison and Rennie, 1997). Due to the poor efficacy of currently available tocolytic agents, attempts to address this problem clinically have been largely unsuccessful (Goldenberg and Rouse, 1998; Gyetvai et al., 1999). There is therefore a need to investigate scientifically novel methods of uterine relaxation where tocolytic potential may be identified.

The state of contractility of smooth muscle is regulated by both intracellular calcium concentration $\left(\left[\mathrm{Ca}^{2+}\right]_{\mathrm{i}}\right)$ and by the calcium sensitivity of myofilaments (Wray, 1993). For the former mechanism, an increase in $\left[\mathrm{Ca}^{2+}\right]_{\mathrm{i}}$ results in phosphorylation of myosin light chain (MLC) catalysed by the calcium-calmodulin-activated myosin light chain kinase (MLCK). The process of calcium sensitization refers to an increase in smooth muscle tension and/or phosphorylation of MLC at a constant $\left[\mathrm{Ca}^{2+}\right]_{i}$. Smooth muscle relaxation occurs as a result of dephosphorylation of myosin light chains by a phosphatase known as myosin light chain phosphatase (MLCP).

For calcium sensitization, it is now clear that a small G-protein, RhoA, is associated with inhibition of MLCP (Uehata et al., 1997; Kunihiko et al., 1999). RhoA is a monomeric G-protein which is active when it contains GTP and inactive when the bound nucleotide is GDP (Somlyo and Somlyo, 2000). Although the precise mechanism of action has not been fully elucidated, two target proteins of RhoA, rho-associated coil-forming protein kinase (ROCK I, also called p160ROCK), and its isoform, ROCK II (also known as $\mathrm{ROK} \alpha$ or Rho kinase) have been reported as having a key role in the RhoA-mediated $\mathrm{Ca}^{2+}$ sensitization. These target proteins are collectively known as Rho kinases and their activation enhances RhoA-mediated calcium sensitization and smooth muscle contractility. In recent years, specific inhibitors of Rho kinases have been investigated as smooth muscle relaxant agents (Kawada et al., 1999; Ishizaki et al., 2000). Y-27632 [(+)-(R)-trans-4-(1-aminoethyl- $N$-4-pyridil)cyclo-

(C) European Society of Human Reproduction and Embryology 
hexanecarboxamide dihydrochloride] is widely used as a specific inhibitor of the ROCK family of protein kinases (ROCK I and II) (Fu et al., 1998; Nakahara et al., 2000; Sward et al., 2000). It appears that it exerts this activity by competing with ATP for binding to the kinases (Ishizaki et al., 2000).

There are no data outlining the expression of RhoA, ROCK I or ROCK II in human pregnant myometrium or the effects of ROCK inhibition on myometrial contractility. The aims of this study were to investigate the expression of RhoA, ROCK I and ROCK II in human pregnant myometrium, to evaluate the effects of the Rho kinase inhibitor Y-27632 on contractions of human isolated myometrium during pregnancy and to compare these effects with those of the calcium channel blocker nifedipine.

\section{Materials and methods}

\section{Tissue collection}

Biopsies of human myometrial tissue during pregnancy were obtained at elective Caesarean section. The biopsies were excized from the upper lip of the lower uterine segment incision in the midline, i.e. upper portion of lower uterine segment. Ethical committee approval for the study was obtained from the Research Ethics Committee at University College Hospital, Galway and recruitment was by written informed consent. All Caesarean sections were performed at term (38-41 weeks gestation), prior to the onset of labour. Immediately upon collection, tissue was placed in Krebs-Henseleit physiological salt solution of the following composition: $\mathrm{KCl} 4.7 \mathrm{mmol} / \mathrm{l}, \mathrm{NaCl}$ $118 \mathrm{mmol} / \mathrm{l}, \mathrm{Mg}_{2} \mathrm{SO}_{4} 1.2 \mathrm{mmol} / \mathrm{l}, \mathrm{CaCl}_{2} 1.2 \mathrm{mmol} / \mathrm{l}, \mathrm{KPO}_{4} 1.2 \mathrm{mmol} / \mathrm{l}$, $\mathrm{NaHCO}_{3} 25 \mathrm{mmol} / \mathrm{l}$ and glucose $11 \mathrm{mmol} / \mathrm{l}$ (Sigma-Aldrich, Dublin, Ireland). Tissue for in-vitro contractility studies was stored at $4^{\circ} \mathrm{C}$ and used within $12 \mathrm{~h}$ of collection. For RNA extraction/RT-PCR, myometrial tissues $(n=3)$ were rinsed in normal saline immediately upon receipt, snap-frozen in liquid nitrogen and stored at $-70^{\circ} \mathrm{C}$.

\section{Tissue bath experiments}

Longitudinal myometrial strips were dissected, measuring $\sim 2 \times 2 \times 10 \mathrm{~mm}$, and mounted under $2 \mathrm{~g}$ of tension in organ tissue baths for isometric recording as previously described (Morrison et al., 1993; Slattery et al., 2001). The tissue baths contained $20 \mathrm{ml}$ of Krebs-Henseleit physiological salt solution which was maintained at $37^{\circ} \mathrm{C}, \mathrm{pH} 7.4$ and gassed continuously with a mixture of $95 \%$ $\mathrm{O}_{2} / 5 \% \mathrm{CO}_{2}$. Myometrial strips were allowed to equilibrate for at least $1 \mathrm{~h}$ before the addition of oxytocin as a utero-tonic agent. The Krebs-Henseleit physiological salt solution in the tissue baths was changed every 15 min during the equilibration period.

After equilibration, contractions were stimulated by bath exposure of the strips to oxytocin $(0.5 \mathrm{nmol} / \mathrm{l})$. The mechanical response of tissues was measured by calculation of the integral of selected areas for 20 min periods using the PowerLab hardware unit and Chart v3.6 software (AD Instruments, Hastings, UK). The integrated tension for the first 20 min after bath addition of oxytocin was calculated and this value served as a control since no significant spontaneous reduction in myometrial contractility was observed over the duration of experiments in control strips. The Rho kinase inhibitor Y-27632, or the calcium-channel blocker nifedipine, were then added to the bath, in a cumulative manner, at increasing bath concentrations (1 nmol/l, $10 \mathrm{nmol} / \mathrm{l}, 100 \mathrm{nmol} / \mathrm{l}, 1 \mu \mathrm{mol} / \mathrm{l}, 10 \mu \mathrm{mol} / \mathrm{l}$ and $100 \mu \mathrm{mol} / \mathrm{l})$ at $20 \mathrm{~min}$ intervals. The cumulative increases in bath concentration of Y-27632 or nifedipine were achieved in a pattern of

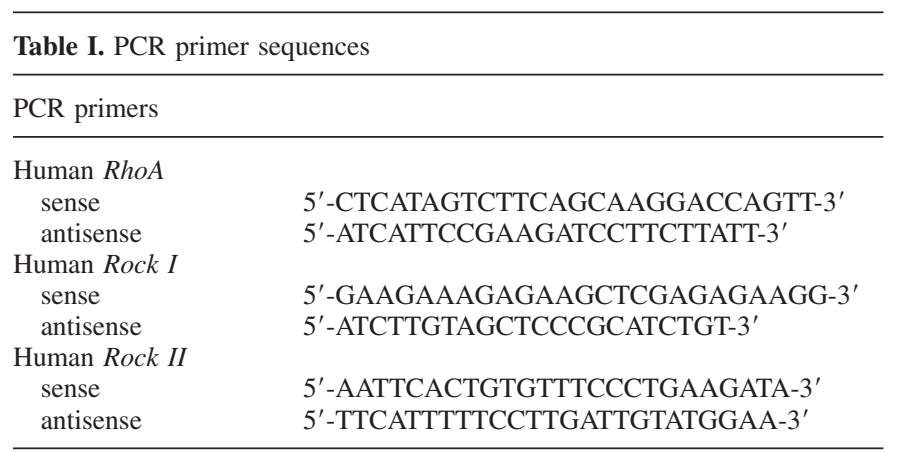

one $\log$ molar increase every $20 \mathrm{~min}$ (i.e. $1 \mathrm{nmol} / \mathrm{l}, 10 \mathrm{nmol} / \mathrm{l}$, $100 \mathrm{nmol} / \mathrm{l}$ etc.). This allowed for a maximum bath exposure of the strip to utero-relaxant of 100-120 min. Control experiments testing for tachyphylaxis revealed no difference between isolated exposure and cumulative exposure during this time. A separate series of experiments using vehicle only was performed. The effects of Y-27632 and nifedipine were assessed by expressing the integral calculated during the 20 min period following addition of each drug concentration as a percentage of the integral obtained in the $20 \mathrm{~min}$ period prior to any drug addition (i.e. percentage contractility).

\section{RNA extraction and reverse transcription}

Total RNA was isolated using TRIzol reagent (Life Technologies, Grand Island, NY, USA) (Chromczynski, 1993). RNA was then reverse-transcribed into complementary DNA (cDNA) for use as a template for PCR. $1 \mu \mathrm{g}$ of RNA was DNaseI-treated (Life Technologies Inc., Gaithersburg, MD, USA). The RNA samples were then denatured at $65^{\circ} \mathrm{C}$ for $10 \mathrm{~min}$. Reverse transcription was performed at $42^{\circ} \mathrm{C}$ for $60 \mathrm{~min}$ in a reaction volume of $20 \mu \mathrm{l}$ containing the following: oligo dT primer (500 ng), Maloney murine leukaemia virus (M-MLV) reverse transcription buffer $[50 \mathrm{mmol} / \mathrm{l}$ Tris- $\mathrm{HCl} \mathrm{pH}$ 8.3, $75 \mathrm{mmol} / \mathrm{l} \mathrm{KCl}, 3 \mathrm{mmol} / 1 \mathrm{MgCl}_{2}, 10 \mathrm{mmol} / \mathrm{l}$ dithiothreitol (DTT)] (Promega, Madison, WI, USA), diethylpyrocarbonate (DEPC)-treated water (BDH, Poole Dorset, UK), deoxyribonucleotide triphosphates (dNTP) $(0.1 \mathrm{mmol} / \mathrm{l})$ (Promega) and $200 \mathrm{IU}$ M-MLV reverse transcriptase (Promega). Reverse transcriptase activity was stopped by heating samples at $65^{\circ} \mathrm{C}$ for $10 \mathrm{~min}$. Control RNA samples, in which no reverse transcription enzyme was added, were included to confirm that no genomic DNA contamination was present.

\section{PCR}

Five $\mu$ l of this $20 \mu \mathrm{l}$ reaction was then used in the subsequent PCR. PCR was performed in a final volume of $50 \mu \mathrm{l}$ containing $1.5 \mathrm{mmol} / \mathrm{l}$ $\mathrm{MgCl}_{2}, 10 \mathrm{mmol} / \mathrm{l}$ Tris- $\mathrm{HCl}, 50 \mathrm{mmol} / \mathrm{l} \mathrm{KCl} \mathrm{pH} 8.3$ (BoehringerMannheim GmbH, Germany), $1.25 \mathrm{U}$ Taq DNA polymerase (Boehringer-Mannheim), $40 \mu \mathrm{mol} / \mathrm{l} \mathrm{dNTP} \mathrm{(Promega)} \mathrm{and} 0.2 \mathrm{pmol}$ of each sense and antisense primer. cDNA amplification was carried out by an initial denaturation step of $5 \mathrm{~min}$ at $95^{\circ} \mathrm{C}$ followed by 45 cycles of denaturation at $94^{\circ} \mathrm{C}$ for $20 \mathrm{~s}$, annealing at $55^{\circ} \mathrm{C}$ for $45 \mathrm{~s}$ and elongation at $72^{\circ} \mathrm{C}$ for $20 \mathrm{~s}$. A total of $5 \mu \mathrm{l}$ of each PCR product was then separated by gel electrophoresis on a $1.2 \%$ agarose gel. Products were run alongside a 100 bp DNA mass ladder (Sigma, St. Louis, MI, USA) for sizing.

Primers used were designed to published mRNA sequences from GenBank; RhoA accession code L25080, ROCK I accession code XM_008814, ROCK II accession code XM_002676 (Table I).

\section{Drugs and solutions}

A stock solution of oxytocin (Sigma-Aldrich, Dublin, Ireland) $(1 \mathrm{mmol} / \mathrm{l})$ was made in ethanol. Y-27632 was kindly donated by 


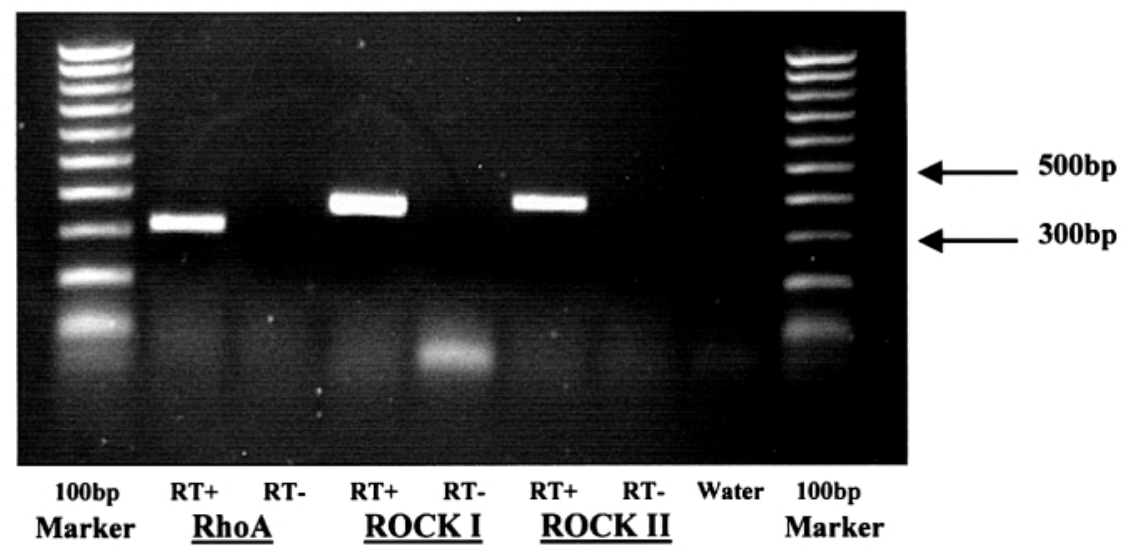

Figure 1. Representative agarose gel stained with ethidium bromide demonstrating expression of RhoA, ROCK I and ROCK II mRNA in human pregnant myometrium $(n=1)$. Reverse transcriptase-negative (RT-) controls for each candidate gene are shown alongside reverse transcriptase-positive $(\mathrm{RT}+)$ PCR products. A water control is also included (no cDNA template).

Welfide Corporation, Osaka, Japan. A stock solution (1 mmol/l) was prepared using deionized water. A stock solution $(1 \mathrm{mmol} / \mathrm{l})$ of nifedipine (Roche Pharmaceuticals, Lewes, UK) was prepared using dimethyl sulphoxide DMSO (Sigma-Aldrich). Series of dilutions as required were made using deionized water on the day of experimentation and were maintained at room temperature for the duration of the experiment. A maximum 0.1\% DMSO was allowed in the tissue-bath. Fresh Krebs-Henseleit physiological salt solution was made daily.

\section{Statistical analysis}

Using the calculated integrals of contractile activity at each bath concentration, dose-response curves were analysed by fitting the logistic equation: $Y=\left(Y_{\max } \times D_{\mathrm{H}}^{n}\right) /\left(\mathrm{EC}_{50}+D_{\mathrm{H}}^{n}\right)$, where $Y$ is the response (percentage contractility), $Y_{\max }$ is the maximal relaxation achieved, $D$ the concentration of agonist (Y-27632 or nifedipine), $n_{\mathrm{H}}$ the slope function, and $\mathrm{EC}_{50}$ the agonist concentration giving the half maximal response. Curve fitting was performed with the software package Prism $^{\text {TM }}$ (Graphpad Software, San Diego, USA). Student's $t$-test was used to compare $\mathrm{pD} 2$ and maximum response values. The statistical package GBSTAT version 6.5 (Dynamic Microsystems, Silver Spring, MD, USA) was used for statistical calculations. A value of $P<0.05$ was accepted as statistically significant.

\section{Results}

Myometrial biopsies were obtained from a total of 19 women. All Caesarean sections were performed under regional anaesthesia prior to labour onset. There were no medical complications of pregnancy. Women who had received exogenous prostaglandins or oxytocin were excluded from the study. The demographic details of the women included were as follows: age range 21-38 years (median 33 years); gestation range 38-41 weeks (median 39 weeks); parity $0-4$. The reasons for Caesarean section were breech presentation, previous Caesarean section and abnormal fetal position.

The three primer sets yielded PCR products of the expected sizes $(n=3)$ (Figure 1). Amplification with the RhoA primer set resulted in a 309 bp PCR product. This product was sequenced (MWG-Biotech Ltd, Milton Keynes, UK) and the results verified that it was part of the RhoA gene. Amplification of myometrial cDNA with ROCK I and ROCK II primers yielded 369 and 390 bp products which sequence analysis confirmed were part of the ROCK I and ROCK II gene sequences. PCR of the reverse transcriptase-negative controls (RT-) showed no amplification confirming no genomic DNA contamination. Similarly the PCR-negative control (no cDNA template) showed no amplification.

The ROCK inhibitor Y-27632 (1 nmol/l to $100 \mu \mathrm{mol} / \mathrm{l})$ exerted a potent relaxant effect on myometrial contractility in a concentration-dependent manner in all strips (Figure 2). In Figure 2A, the contractile activity after exposure to oxytocin $(0.5 \mathrm{nmol} / \mathrm{l})$ in a control strip is demonstrated. The inhibitory effect of Y-27632 is shown in Figure 2B. The mean $\mathrm{pD}_{2}$ value was $7.63 \pm 0.38$ and the mean net relaxant effect at maximum bath exposure was $72.3 \% \pm 6.1(n=6)$. The calcium channel blocker nifedipine also exerted a potent relaxant effect on myometrial contractility and a representative recording demonstrating this is shown in Figure $2 \mathrm{C}$. The mean $\mathrm{pD}_{2}$ value was $7.24 \pm 0.48$ and the mean net relaxant effect at maximum bath exposure was $93.4 \% \pm 3.1(n=6)$. There was no significant difference between the $\mathrm{pD}_{2}$ values for nifedipine and Y-27632 $(P=0.469)$ (Table II). The mean net maximum relaxant effect for nifedipine $(93.4 \% \pm 3.1)$ was greater than that observed for Y-27532 $(72.3 \% \pm 6.1)(P=0.028)$. The dose-response curves for the effects of Y-27632 and nifedipine on myometrial contractions are shown in Figure 3.

\section{Discussion}

The results from this study clearly demonstrate expression of RhoA, ROCK I and ROCK II mRNA in human pregnant myometrium and that the Rho kinase inhibitor Y-27632 results in potent inhibition of human isolated myometrial contractility in tissue obtained in the third trimester of pregnancy. Y-27632 is a highly selective ROCK inhibitor (Uehata et al., 1997; Ishizaki et al., 2000) and therefore results in reduced RhoAmediated calcium sensitization and inhibition of smooth muscle contractility. This is the first report to our knowledge outlining the effects of ROCK inhibitors on uterine contractility and highlights their potential as novel tocolytic agents. In addition to the potential pharmacological applications of these compounds for inhibition of uterine contractions, our results raise 

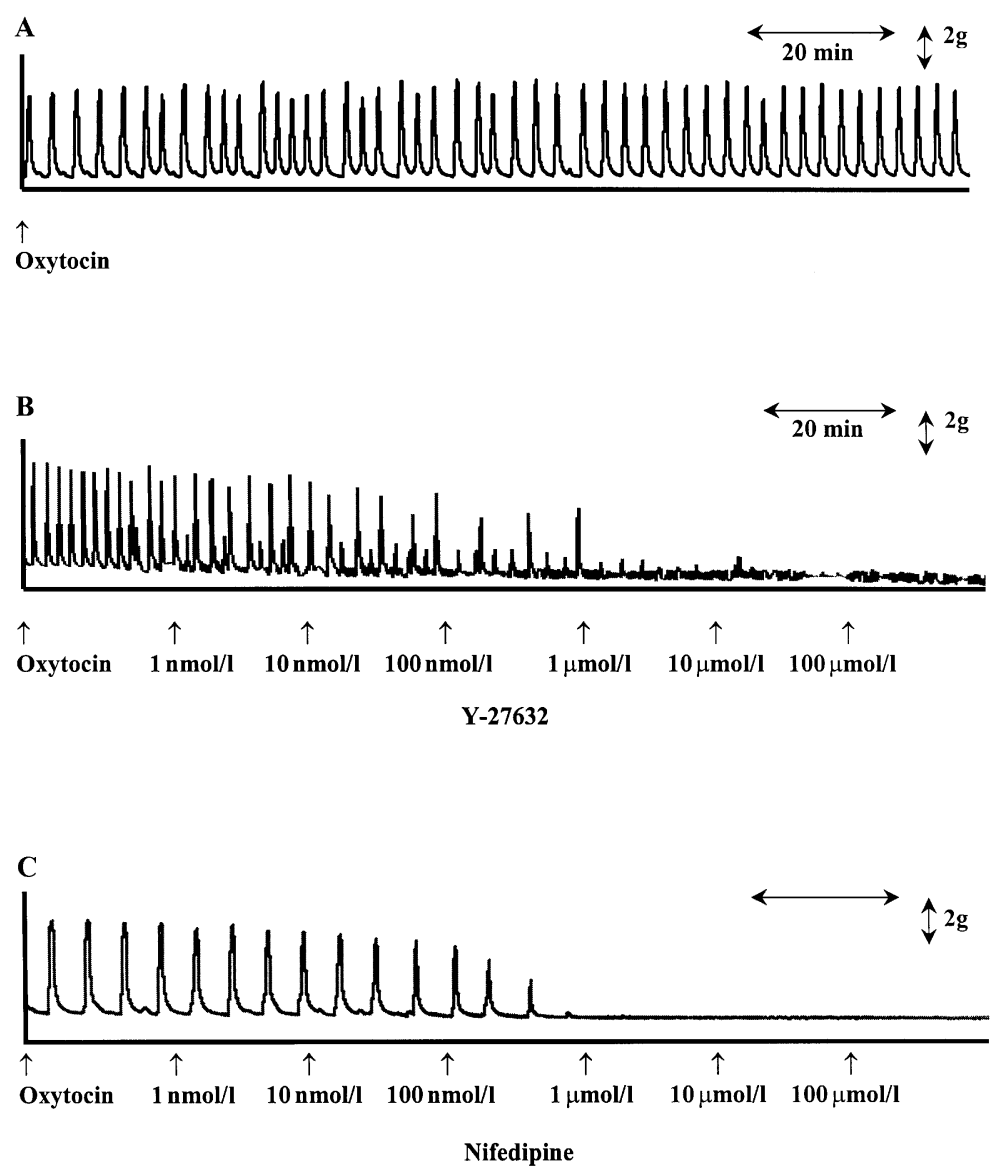

Figure 2. Representative recordings of oxytocin-stimulated $(0.5 \mathrm{nmol} / \mathrm{l})$ contractions in pregnant human myometrium are shown. (a) Recording from a control strip and no further drug additions were made following incubation with oxytocin. (b and c) Effects of cumulative additions of Y-27632 and nifedipine respectively $(1 \mathrm{nmol} / \mathrm{l}, 10 \mathrm{nmol} / \mathrm{l}, 100 \mathrm{nmol} / \mathrm{l}, 1 \mu \mathrm{mol} / \mathrm{l}, 10 \mu \mathrm{mol} / \mathrm{l}$ and $100 \mu \mathrm{mol} / \mathrm{l})$ at 20 min intervals.

Table II. Relaxant effects of Y-27632 and Nifedipine

\begin{tabular}{lll}
\hline & $\mathrm{pD}_{2}$ & Maximum inhibition $(\%)$ \\
\hline (A) Y-27632 $(n=6)$ & $7.6 \pm 0.3$ & $72.3 \pm 6.1$ \\
(B) Nifedipine $(n=6)$ & $7.2 \pm 0.4$ & $93.4 \pm 3.1^{*}$ \\
\hline
\end{tabular}

*A versus B: $P=0.028$.

Values are given for $\mathrm{pD}_{2}$ values and the percentage maximum mean net relaxant effects $( \pm$ SEM) of Y-27632 and nifedipine on oxytocin-stimulated contractions in human pregnant myometrial tissue. $n=$ number of subjects in each group.

the issue of the possible physiological significance of Rho kinase activity in human myometrium. Little is known about its role in maintenance of uterine quiescence during pregnancy or in regulation of onset and/or maintenance of human parturition. It has been reported that expression of Rho kinase isoforms is up-regulated in rat myometrium in late pregnancy (Niiro et al., 1997). Up-regulation of the proteins for ROCK I and ROCK II has been demonstrated in human pregnant myometrium in comparison to non-pregnant myometrium (Moore et al., 2000). This has led to suggestions that increased endogenous Rho kinase activity, resulting in enhanced RhoAmediated calcium sensitization, may be involved in the increased contractility that occurs at the time of labour onset at term.

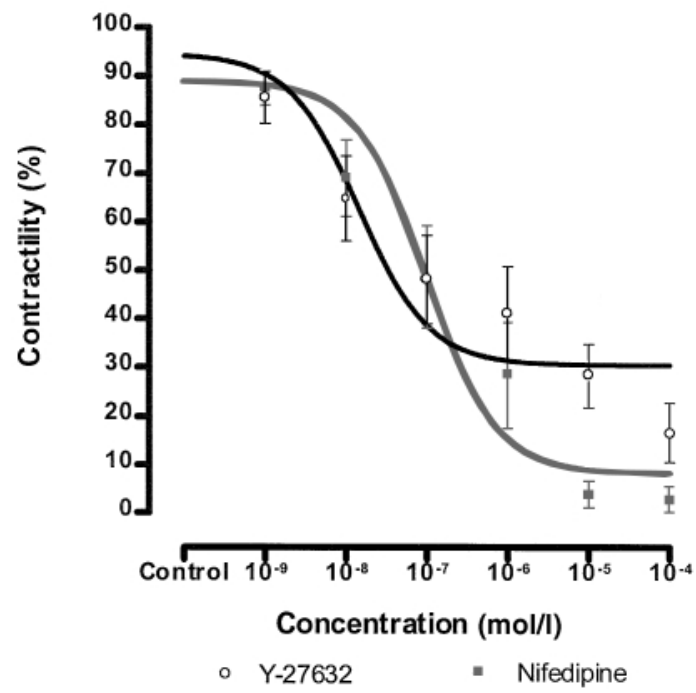

Figure 3. Sigmoidal dose-response curves showing the effects of cumulative additions of Y-27632, and nifedipine $(1 \mathrm{nmol} / \mathrm{l}$, $10 \mathrm{nmol} / \mathrm{l}, 100 \mathrm{nmol} / \mathrm{l}, 1 \mu \mathrm{mol} / \mathrm{l}, 10 \mu \mathrm{mol} / \mathrm{l}$ and $100 \mu \mathrm{mol} / \mathrm{l})$ at $20 \mathrm{~min}$ intervals on oxytocin-stimulated $(0.5 \mathrm{nmol} / \mathrm{l})$ contractions on pregnant human myometrium. Percentage contractility is shown on the $y$-axis and concentration of drug on the $x$-axis. Open circles represent Y-27632 and closed squares represent nifedipine. Values shown are means and vertical error bars represent SEM. 
We compared the effects of Y-27632 with those of nifedipine on isolated human pregnant myometrial contractions. The reasons for this were 2-fold. Nifedipine, in contrast to Y-27632, is a calcium channel blocker and hence reduces intracellular calcium (Saade et al., 1994). Secondly, nifedipine has been used clinically for tocolysis although there are concerns about its efficacy and possible adverse effects (Richichi and Vasilenko, 1992). While Y-27632 was a potent utero-relaxant agent in our studies, we found that nifedipine exhibited a greater mean net relaxant effect. These findings are in agreement with other in-vitro myometrial studies where nifedipine appears to be the most potent uterine relaxing agent (Saade et al., 1994). The possible clinical significance of this is unknown. However, it is clear that the Rho kinase pathway is essential for smooth muscle contraction (Fukata et al., 2001) and that future research directed at its role in human myometrium may be of benefit for effective treatment of preterm labour. For clinical tocolysis, clinical trials would be necessary to evaluate potential efficacy and safety.

There are further issues for consideration in the interpretation of our results. Firstly, we did not explore the possibility of an alternative mechanism of action of Y-27632 in achieving myometrial relaxation. Other studies in various tissue systems have revealed that it is a highly selective inhibitor of the Rho kinase enzymes (Uehata et al., 1997; Ishizaki et al., 2000) and hence have indicated its mechanism of action. Secondly, all our studies were carried out in myometrial tissue obtained from the lower uterine segment. While the findings may not similarly apply to myometrial tissue obtained from the uterine fundus, this seems unlikely as there appears to be no difference in contractile properties between myometrial tissues obtained from upper and lower uterine sites (Luckas and Wray, 2000).

In conclusion, RhoA, ROCK I and ROCK II are expressed in human pregnant myometrium and pharmacological inhibition of Rho kinase activity/RhoA-mediated calcium sensitization results in potent relaxation of isolated human myometrial contractility during the late third trimester of pregnancy. Further research is required to elucidate the role of this pathway in the physiology of human parturition and the clinical therapeutic implications for preterm labour.

\section{Acknowledgements}

We are grateful to Welfide Corporation, Japan for the gift of Y-27632. We wish to acknowledge the Health Research Board of Ireland, the Higher Education Authority of Ireland and BioResearch Ireland for research funding.

\section{References}

Burke, C. and Morrison, J.J. (2000) Perinatal factors and preterm delivery in an Irish obstetric population. J. Perinat. Med., 28, 49-53.

Chromczynski, P. (1993) A reagent for the single-step simultaneous isolation of RNA, DNA and proteins from cell and tissue samples. BioTechniques, 15, 532-534, 536-537.
Fu, X., Gong, M.C., Jia, T., Somlyo, A.V. and Somlyo, A.P. (1998) The effects of the Rho-kinase inhibitor Y-27632 on arachidonic acid-, GTP $\gamma \mathrm{S}-$, and phorbol ester induced $\mathrm{Ca}^{2+}$-sensitisation of smooth muscle. FEBS Lett., 440, 183-187.

Fukata, M., Amano, M. and Kaibuchi, K. (2001) Rho-Rho-kinase pathway in smooth muscle contraction and reorganization of non-muscle cells. Trends. Pharmacol. Sci., 22, 32-9.

Goldenberg, R.L. and Rouse, D.J. (1998) Prevention of premature birth. $N$. Engl. J. Med., 339, 313-320.

Gyetvai, K., Hannah, M.E., Hodnett, E.D. and Ohlsson, A. (1999) Tocolytics for pre-term labour: a systematic review. Obstet. Gynecol., 94, 869-877.

Ianuchi, T.A., Tomich, P.G. and Gianopolus, J.G. (1996) Etiology and outcome of extremely low-birth-weight infants. Am. J. Obstet. Gynecol., 174, 1896-1902.

Ishizaki, T., Uehata, M., Tamechika, I., Keel, J., Nonomura, K. and Maekawa, M. (2000) Pharmacological properties of Y-27632, a specific inhibitor of Rho-associated kinases. Mol. Pharmacol., 57, 976-983.

Kawada, N., Seki, S., Kuroki, T. and Kaneda, K. (1999) ROCK inhibitor Y-27632 attenuates stellate cell contraction and portal pressure increase induced by endothelin-1. Biochem. Biophys. Res. Commun., 266, 296-300.

Kunihiko, I., Akihiro, Y. and Koichi, S. (1999) A major role for the Rhoassociated coiled coil forming protein kinase in $\mathrm{G}$-protein-mediated $\mathrm{Ca}^{2+}$ sensitisation through inhibition of myosin phosphatase in rabbit trachea. Br. J. Pharmacol., 128, 925-933.

Luckas, M.J. and Wray S. (2000) A comparison of the contractile properties of human myometrium obtained from the upper and lower uterine segments. Br. J. Obstet. Gynaecol., 107, 1309-1311.

Moore, F., Da Silva, C., Wilde, J.L., Smarason, A., Watson, S.P. and Lopez Bernal, A. (2000) Up-regulation of p21- and RhoA-activated protein kinases in human pregnant myometrium. Biochem. Biophys. Res. Commun., 269, 322-326.

Morrison, J.J., Ashford, M.L., Khan, R.N. and Smith, S.K. (1993) The effects of potassium channel openers on isolated pregnant human myometrium before and after the onset of labour: potential for tocolysis. Am. J. Obstet. Gynecol., 169, 1277-1285.

Morrison, J.J. and Rennie, J.M. (1997) Clinical, scientific and ethical aspects of fetal and neonatal care at extremely preterm periods of gestation. $B r . J$. Obstet. Gynaecol., 104, 1341-1350.

Nakahara, T., Moriuchi, H., Yunoki, M., Sakamato, K. and Ishii, K. (2000) Y-27632 potentiates relaxant effects of $\beta_{2}$-adrenoceptor agonists in bovine smooth muscle. Eur. J. Pharmacol., 389, 103-106.

Niiro, N., Nishimura, J., Sakihara, C., Nakano, H. and Kanaide, H. (1997) Up-regulation of rho $\mathrm{A}$ and rho-kinase mRNAs in the rat myometrium during pregnancy. Biochem. Biophys. Res. Commun., 230, 356-359.

Richichi, J. and Vasilenko, P. (1992) The effects of nifedipine on pregnancy outcome and morphology of the placenta, uterus and cervix during late pregnancy in the rat. Am. J. Obstet. Gynecol., 167, 797-803.

Saade, G.R., Taskin, O., Belfort, M.A., Erturan, B. and Moise, K.J. Jr (1994) In vitro comparison of four tocolytic agents, alone and in combination. Obstet. Gynecol., 84, 374-378.

Slattery, M.M., O’Leary, M.J. and Morrison, J.J. (2001) Effect of parathyroid hormone-related peptide (PTHRP) on human and rat myometrial contractility in vitro. Am. J. Obstet. Gynecol., 184, 625-629

Somlyo, A.P. and Somlyo, A.V. (2000) Signal transduction by G-proteins, Rho-kinase and protein phosphatase to smooth muscle and non-muscle myosin II. J. Physiol., 522, 177-185.

Sward, K., Dreja, K., Susnar, M., Hellstrand, P., Hartshorne, D.J. and Walsh, M.P. (2000) Inhibition of Rho-associated kinase blocks agonist-induced $\mathrm{Ca}^{+}$sensitisation of myosin phosphorylation and force in guinea-pig ileum. J. Physiol., 522, 33-49.

Uehata, M., Ishizaki, T., Satoh, H., Ono, T., Kawahara, T. and Morishita, T. (1997) Calcium sensitisation of smooth muscle mediated by a Rhoassociated protein kinase in hypertension. Nature, 389, 990-994.

Wray, S. (1993) Uterine contraction and physiological mechanisms of modulation. Am. J. Physiol., 264, C1-18.

Received on April 9, 2001; resubmitted on August 24, 2001; accepted on November 11, 2001 